\title{
Communication of the Organization
}

Communication always takes place by means of symbols. Information must be coded by the sender, i.e. expressed by the use of symbols (mostly language symbols), and then decoded by the recipient. The process of message decoding may be divided into two stages: the acquisition and the interpretation of the message, so-called "understanding" through the attaching of the meaning to symbols, which made up the message. Itself the understanding of the message is a not a sufficient condition of communication, as it may happen so, that the recipient interprets (understands) the message in a more or less different way from what the sender intended to transfer, what in practice may lead to the consequences more or less similar to the total impossibility of decoding the message. We may speak about communication only if the meanings attached by the sender to the individual symbols are close or identical to the meanings attached to these symbols by the recipient.

There are many communication models; however, the majority of them are too simple to reflect the communication process in the organizations precisely. The simplest is the linear model, which provides for the presence of the sender, recipient and the message code. The issue of the message aim is analyzed in the model of H. Lasswell. For the identification of the message aim Lasswell suggests the analysis of the sender, contents, selected media, auditorium and the result of the acquisition of the message.

The model of C.E. Shannon and W. Weaver provides for the possible distortions (noise) in the process of the message transfer between sender and recipient. This model is composed of eight elements: the source (sender, transmitter), the message (the message contents), the coder for the conversion of the message into the symbolic language, the channel (medium) with a different throughput, the decoder for the inverting the coding

\footnotetext{
* Prof. zw. dr hab., Wyższa Szkoła Finansów i Zarządzania w Warszawie.
} 
process, the recipient, the feedback and the noise. The role attached to the noise, is accounted to the fact that this model was worked out for the purpose of telecommunication, not for social communication (Zalewska, 2006: 157).

Even more complicated is the model taking into account the existence of a feedback between the sender and recipient of the message as a factor affecting the communication process. This model presupposes that the role of message sender and recipient is relative; the sender is often a recipient (if we include non-verbal signals, for example). Moreover, it should be noticed that return message might be sent through the same channel as the received information or through some other channel. The latter case is apparent when the return message is an action taken by the recipient in reply to the received message. The absence of the return message may mean that the initial message did not come to the recipient, i.e. was distorted through the fault of transmission channel or was not understood. The return message is of minor importance if the transferred information is simple, and does not require significant accuracy of understanding, and have to be transferred quickly.

In the opinion of D. McQuail, communication as it is, takes place at several levels, which were represented by the author as a pyramid. The place of the communication surface in this scheme depends on the number of communication acts put over on it. Thus, on the basis of the pyramid lies intrapersonal communication, which contains the largest number of communication acts taking place only in the mind of the communication participant, who considers various options of formulating the message. The highest level is occupied by interpersonal communication (between two or three individuals), which is followed by the group communication (communication within social groups), institutional communication, organizational and mass communication.

G.R. Miller' model, besides sender, recipient, code and channel, allows for the attitude, live experience of the sender and recipient and finally, situational context. In the model of W. Schramm the emphasis falls on the multiple aspects and complexity of communication process. In this model the sender and the recipient of the message are not defined, it presupposed, however, that the transmission and coding of messages occur simultaneously between the participants of the communication. There is also an intermediary model, which both provides for the presence of sender and recipient, and acknowledges the simultaneity of transmitting and receiving of messages. The participant of communication simultaneously transmits messages through one or more channels, and at the same time, as a recipient, he decodes the messages transmitted through other channels (Stankiewicz, 2006).

Communication in the organization depends not only on the organizational structure, but also on other composite elements of the organization, i.e. goals, people and technical appliances. All these factors affect the communication process in the organization.

The communication method, i.e. the selection of the message recipient and message contents, depends primarily on the position of the individual in the structure of the organization. The method of the accomplishment of aims- both organization's aims and communication aims such as explanation, instructing, informing, motivating and establishing good relations, etc. also depends on the position of the individual in the organization. The strong dependence between communication aims and the structure of 
the organization is obvious. "Downward" communication (message transfer from managers to subordinates) includes explanation, motivating, instructing and certainly, informing. This kind of communication often starts on the top of the organizational structure; messages are transmitted gradually to lower structural levels, and, finally, to the executors. In the "upward" direction of communication the information is transferred in the reverse direction. The aim of such communication is the transfer of information from executors to the superiors, so it contains no motivation and instructing. "Upward" communication is more susceptible to the distortion, as the information passes through certain levels of management, where it is filtered and selected; therefore, low- level managers consider some information to be unimportant for their subordinates (Griffin, 1998: 563). The tendency towards the building up good relations is typical to the participants of "horizontal" communication (between the employees of the same structural units of the organization). Formal communication procedures, apparent in two previous communication types, do not take place here.

The organizational structure is a cause of next problem in creating the open surrounding for communication. The hierarchical structure of organisation that divides enterprise on departments, divisions etc., makes the communication harder (Staniewski, 2004: 94).

The necessary condition for the communication process (in contrast to a single communication act and one-way communication) is feedback. One can distinguish two types of feedback: evaluative feedback (positive or negative) and descriptive. Positive estimating feedback causes the keeping of contact and the impression that the interlocutor is the most important element of communication. Feedback is important for motivating of employees to the implementation of their tasks. Negative feedback is particularly important for the correct process of communication aiming at transferring of the information; such feedback enables the sender to make sure that his message was wrongly interpreted. On the other hand, negatively evaluating return messages may cause the defence reaction of the speaker and the cessation of communication. Finally, descriptive feedback enables to acquire information about the emotional attitude of the message recipient to the contents of transferred message and assists in the clear definition of ideas or makes an individual think over certain matters.

In the direct contacts between people the attention of the sender is concentrated on the recipient. This means that the way of interpreting the message depends not only on the sender's intention and the form of his message, but also on the way the sender is regarded by the participants of the organization (i.e. his competence, knowledge, experience, prestige, convictions, etc.) (Potocki, 2001: 12). Direct contacts of the participants of the organization enable to differentiate between communication and conversation. In the first case the aim of the sender is to gain certain benefits (for example, the implementation of some task by the recipient) or an intention to initiate common actions. In the second case the aim is primarily to support informal relations between people and the satisfaction of personal curiosity or the need for an approval (Grzesiuk, Trzebiñska, 1978: 23). As this informal discourse is not related to the organization's aims, causes the time waste, a lot of managers often consider it to be worthless and therefore suggest the limitation of it to 
a minimum. On the other hand, such discourse causes the "integration" of the team, which is one of the fundamental conditions for the productivity and engagement into work.

One should also differentiate between explicit knowledge (related to the education and experience of the participants of the organization) and tacit knowledge (depending mostly on intuition and common sense), however, quite frequently helpful in problem solving. Thus, many organizations strive to use this tacit knowledge, carrying up socalled "brainstorms" or other techniques of combination of facts (Nonaka, Takeuchi, 1999). It looks like dissemination and application of information in the organization largely depends on the informal contacts ("conversation").

Depending on the type of transferred information, technical means of communication can be divided into the means enabling the transferring of text, speach and image. Until recently fax was used for the transferring of text messages. Now this role is performed by e-mail (similarly- stationary telephone was substituted by mobile phones). For the successful communication the choice of the means for transferring messages is very important (thus, there is no need to send an e-mail message to a colleague sitting at the desk nearby), as well as the adaptation of the message form to the selected means. Speaking over the telephone, the speakers do not see each other, therefore body language is eliminated from the communication. In the direct conversation, thanks to body language, the speaker may make sure whether the interlocutor listens to the message, whether he agrees with the statement, etc. Thus, the proper choice of words is more important here than in the direct communication (Potocki, Winkler, ${ }^{-}$bikowski, 2003: 88). However, the sender may ask the recipient's opinion, so the possibility of the feedback is not totally eliminated. Telephone is an ideal medium of information transfer, if the information must be transferred quickly (Gros, 1993: 11). The choice of the communication channel depends on the needs and requirements of the recipient and the importance of the information. Complicated contents should be transferred through the channel, which will enable recipient's precise and repeated familiarization with the information. Therefore, such information should be transferred in writing. Direct transfer of the message may be the means of motivation of the organization members.

In verbal communication one can distinguish oral and written communication. The difference between them confirms the influence of the transfer medium on the communication method. Thus, written communication is more official (except for the email), limited almost exclusively to the information area (although some role is played by stylistic means); it is characterized by a more thorough description of a certain subject, the absence of the opportunity to acquire an immediate answer and a spatial distance between the communication participants, etc.

One of the statement types, in which verbal, written and visual messaging are combined, are public appearances, i.e. meetings, conferences, conventions, lectures, etc. Some of such appearances (for example, meetings) often make up a steady element of communication structure of the organization. They should have a certain form, i.e. contain a title (topic), precise contents and final summary of main issues. Public appearance (speech) is a message directed at many recipients, therefore the degree of variability and perception capabilities of the auditorium should be considered. It is not only about precision and clarity of the message, achieved by the elimination of symbols, to which the 
majority of recipients attach no meaning, but about the achievement of aims of the public appearance. Therefore, prolixity should be avoided, the speaker should combine verbal and audiovisual messaging, repeat the main issues several times to facilitate memorization, and, in case of long statements, apply short breaks in the form of anecdotes.

The implementation of aims requires transmission of information about these aims to individual units within the organization. This information must be transferred in the way understandable to each of the organization members; therefore it should take into account individual features and competences. Messages, concerning the aims of the activity should not contain incomprehensible concepts, unclear interpretations of previous assumptions and modifications of activity plans, unclear from the point of view of individual units.

The transmission of precise and clear information about the aims of the organization's activities is important from the point of view of personal motivation of the organization members and their engagement in the accomplishment of these aims. The degree of such engagement depends not only on concrete needs of the individual, but also on his estimation of chances for the eventual success or failure of the activity. Such estimation is possible only if the individual possesses adequate knowledge about aims and strategy of activities.

From the perspective of motivation, supervision and control within the organization the form of messages is very important. Messages about the aims should be adequate, i.e. contain no statements expressing personal evaluation, like "in my opinion" or "I believe", etc. The one-way transmission (so-called transmission from managers to the individual units and employees) is also insufficient, as it provides no guarantee, whether the information was understood according to the intention of the sender. Only return message enables to estimate whether messages about the aims were understood in a proper way and gives an opportunity to supplement the information or correct the wrong interpretation of it.

An important role in the communication is played by the employees' satisfaction with the implemented work and the interrelations of the employees; one can see an inverse relation, as the general atmosphere in the organization and the engagement of its members affect the quality of communication.

The distortions in the communication process are caused either by an improper selection of the channel (medium) of transmitting or by the improper adaptation of the message form (the system of symbols) to the opportunities (competences, education, experience, etc.) of the recipient. In the organization such distortions mainly occur during the exchange of information between individual units, comprising specialists in various branches, using their own professional slang.

Thus, there is a kind of a conflict between the variability of the organization members and conditions for an efficient communication. On one hand, the variability of people and the variability of positive and negative experience, skills in solving various problems and personal features make up the wealth of the organization; on the other hand, such variability may complicate the finding of "a common language" and thus cause distortions in the communication.

Another source of the communication break may be the informational overload of the recipient, which occurs when the recipient receives more information than he is able to 
process. It is vital for the organization to eliminate the information, which is inessential for decision-making (management) and the implementation of the decisions. This can be achieved by arranging the information and the identification of the essential (directive) information areas, according to such arrangement. The needs of the sender and recipient should be its criteria. Another obstacle impeding the communication within the organization is a partial concealment of information by the subordinates, which are afraid of the reaction of the superiors. Partially it is the fault of superiors, which reluctantly accept negative information.

Situational context may also be a factor impeding the communication. This context always accompanies the communication and in some way influences on the meaning of symbols (verbal and particularly non-verbal), however, it does not cause the distortion of the communication if the context is the same for both parties. Although sometimes it happens so, that the communication participants think that the context is the same for the both, but in fact, both sender and recipient interpret this context differently.

The autonomy of group members and the satisfaction with the implemented tasks depend not only on the competences and requirements, but also on the communication structure. We may distinguish several types of communication structure, depending on the relations between the participants of the communication. One of such types is the starstructure, in which individual members of the organization are arranged around a single individual, mostly a leader, occupying a central position. Each message is initially sent to this individual, then it is transferred to the appropriate address. Individual members of the organization have no opportunity to communicate with each other. The opposition to the star-structure is a circle-structure, in which there is no individual, who is a communication centre and controls the whole communication process. Information is transferred from one participant to the other, and each participant may communicate only with two others. The communication structure similar to this one is the chain-structure; the only difference is that in the chain-structure the information turnover is not closed. One more structure type is the one which enables each participant to communicate with any of the other participants.

We may also speak about the communication style, which depends on so-called organizational culture, that is, the existing set of regulations, values and behaviour norms of the members of the organization (Karlof, 1992). The communication style influences on the quality of relations between organization members and on their overall mood. There are four main communication styles: Expresser, Driver, Relater \& Analyst. Each of these styles may be equally successful in different organizations (for example, driver style is appropriate for military organizations or sport teams, expresser style may be successful in scientific or educational institutions, etc.). Within certain communication styles the information turnover may be more or less successful, however the satisfaction of group members depends both on the selection of the appropriate style and on the efficiency in transferring of the information. Only owing to the efficiently functioning communication the organization members can find out whether they are appreciated by the superiors and whether superiors care for them. The communication style may be improved by means of an appropriate psychological training, for example, trainings developing assuredness or openness (Stankiewicz, 2006: 38). All these factors should be taken into account while 
planning the communication structure in the organization with the representatives of diverse cultures.

One should differentiate between the communication channel and information transfer network within the organization. In each organization information is transferred through certain "pathways”, creating an internal information network. „Information system - as C. Sikorski writes - means the way of communication of people within the organization in the existing conditions of the division of labour and the distribution of decision-making powers". The creation of such networks is necessary, as otherwise each member of the organization would have to communicate with all the others, and the quantity of such contacts would drastically increase together with the increase of the organization size.

Such networks may be divided into formal (official) and informal (non-official). Official networks are just a method of information turnover management; they are planned depending on the organization structure and aims, the number of employees, external environment, etc. Non-official networks are formed spontaneously and are used not only for information exchange, but also for supporting friendly relations between organization members.

Each organization should not only possess the system of internal information exchange, but also communicate with the external environment. For the successful and conflict-free functioning of the organization in the social environment the most important issue is the identification of its supreme aim ("mission"). This aim should be expressed in a flexible way, which will enable to adapt it to the changing conditions of environment, but this aim should be sufficiently precise, so that social environment could properly perceive the actual aims of the organization. Defining this aim, one should take into account not only interests and preferences of the organization members (or their most influential members), but also expectations and interests of social environment. From this point of view efficient communication between the organization and its social environment is a key issue (Bielski, 1996: 90).

It is also important to identify cultural diversity and take it into account in the communication process. This diversity always causes the appearance of certain stereotypes, expectations, methods of the appraisal and evaluation, ignorance of which may lead to communication distortions, and even to the break. As it was noticed by G. Hofstede, the organization, the members of which communicate with the representatives of diverse cultures, should consider several essential factors. First of all, the distance between superiors and subordinates (power distance) is differently identified in certain cultures. Besides, one should be aware of the existence of certain values and norms which either do not exist in the native culture, or have a different status in it. The degree of the individual's autonomy in the team (individualism-collectivism) and relations between sexes may also vary (Hofstede, 2000: 21).

The enterprise operating in multi-cultural (cultural diversified) regions is a crucial problem of communication that besets mostly transnational organisations (Staniewski, 2004: 94).

In the conditions of the continuous structural transformations the majority of organizations are forced to introduce regular modifications into their structure, and 
internal communication system. Due to the necessity of such modifications it is vitally important that this system would not block up the inflow of information about the actual status and eventual weaknesses of the organization. The condition for the success of these modifications, alongside with sincerity and openness, is the identification of the problem diagnosis, development of the common vision of the future and the maintenance of the feeling of the absolute need for changes (Nalepka, Buła, Patkaniowski, 2000: 184). Obviously, all these requirements may be fulfilled only in the conditions of the efficiently functioning communication system.

\section{References}

Adler N. J., International Dimensions of Organizational Behavior, Boston 1986.

Bielski M., Organizacje. Istota, struktura procesy, Łódź 1996.

Griffin R.W., Podstawy zarzadzania organizacjami, Wydawnictwo Naukowe PWN, Warszawa 1998.

Gros U., Analiza systemu porozumiewania się w organizacji, „Przegląd Organizacji” 1993 nr 3.

Grzesiuk L., Trzebińska E., Jak ludzie porozumiewaja się?, Warszawa 1978.

Hofstede G., Kultury i organizacje. Zaprogramowanie umystu, Warszawa 2000.

Karlof B., Strategia biznesu, koncepcje i modele, Warszawa 1992.

Morgan P.I., Organizational Behavior and Management, Dubuque 1989.

Nalepka A., Buła P., Patkaniowski M., Sposoby pokonywania oporu wobec zmian w restrukturyzowanych przedsiębiorstwach, [w:] Zmiana warunkiem sukcesu. Opór wobec zmian. Szansa czy zagrożenie?, Skalik J. (ed.), materiały konferencyjne, Lądek Zdrój 1999, Prace Naukowe nr 842 Akademii Ekonomicznej we Wrocławiu, Wrocław 2000.

Newstrom J.W., Davis K., Organisational Business Communication, New York 1989;

Nonaka I., Takeuchi H., Kreowanie wiedzy w organizacji, Warszawa 1999.

Potocki A., Komunikacja wewnętrzna w przedsiębiorstwie, Kraków 2001.

Potocki A., Winkler R., Żbikowska A., Techniki komunikacji w organizacjach gospodarczych, Warszawa 2003.

Ross R., Speech Communication, Englewood Cliffs, 1983.

Staniewski M., Dzielenie się wiedzq w Buckman Laboratories - czyli jak to robili pionierzy, „Zarządzanie Zasobami Ludzkimi”, $2004 \mathrm{nr} 6$.

Stankiewicz J., Komunikowanie się w organizacji, Wrocław 2006.

Zalewska M., Komunikowanie sie jako podstawa relacji spolecznych, [w:] Metody organizacji i zarzadzania. Ksztattowanie relacji organizacyjnych, Błaszczyk W. (ed.), Warszawa 2006. 